\title{
TeAChing With TeChNOLOGY IN ENGINEERING EDUCTION
}

\author{
Darlene Spracklin-Reid, Caroline Koenig, Suzanne Hurley and Pam Phillips \\ Memorial University \\ darlenesr@mun.ca, ckoenig@mun.ca, suzannehurley@rogers.com,pamp@mun.ca
}

\begin{abstract}
Engineering courses present many challenges and opportunities for Instructional Designers. Communicating technical content in an online environment while encouraging and maintaining student engagement is an area of particular interest in instructional design. This paper will examine some of the challenges posed by technical courses and how the instructional design team in the Distance Education Learning and Teaching Support division of Memorial University meets these challenges.
\end{abstract}

Keywords: instructional design, online, engineering education

\section{INTRODUCTION}

The number of online or blended courses is increasing, with $46 \%$ of university graduates having completed at least one online course [1]. At Memorial University, there has been an increase in the number of courses offered entirely online, or with online components, in the Faculty of Engineering and Applied Science.

Blended learning, or b-learning, uses a combination of e-communication and face-to-face interactions. Blearning combines classes and online activities, often incorporating a Learning Management System (LMS) like Desire2Learn and Web 2.0 applications for the use of both students and teachers [2.3].

B-learning provides students with a flexible learning environment that allows them to learn outside of the traditional classroom or lab setting [4]. B-learning is a mixture of independent learning, online learning, and face-to-face activities [4]. ENGI 1030 uses a blend of traditional face-to-face lectures, labs, and online resources including instructional screencasts and self-assessment quizzes in its Desire2Learn course shell. Creating additional screencasts will expand on this b-learning approach.

Studies of b-learning show that students demonstrate higher levels of engagement, and they study more frequently. B-learning can be effective in encouraging students to study outside of class time [5]. Using online videos, tutorial and other resources as part of a b-learning approach encourages ENGI 1010 and ENGI 1030 students to take responsibility for their own learning, helping them to develop lifelong learning skills. B- learning facilitates a greater share of responsibility from the student in the learning process, a greater motivation, and a more satisfactory outcome [2]. The role of the instructor is to motivate the students while showing them the value of what they are learning [3].

ENGI 8151 is taught entirely online to allow students who are working internationally to participate in the course as they are gaining practical experience. Video, text, discussion groups and teamwork are used to build a sense of community.

The Canadian Engineering Accreditation Board (CEAB) requires that graduates possess attributes that include lifelong learning skills so they will have the skills they need to become competent professionals. They require the "ability to identify and to address their own educational needs in a changing world, sufficiently to maintain their competence and contribute to the advancement of knowledge" [6]. Studies suggest that the introduction of alternative methods or pedagogical approaches such as blended and online learning in the engineering teaching-learning process can help to shape the professionals currently demanded by society [3].

\section{ENGINEERING 1010: ENGINEERING STATICS}

\subsection{Course Description}

Engineering 1010 is the first course that students in Memorial University's Faculty of Engineering and Applied Science take in mechanics. Forces and moments are described with vector algebra, leading to a description of the equilibrium conditions for particles and solid bodies. Students learn about the use of free body diagrams and their knowledge is applied to the analysis of trusses, frames and machines. Additional topics include friction, centre of force, centroids and second moments of area.

\subsection{Online Resources}

Engineering 1010 is taught as an on-campus course, however, significant online content has been developed to complement the traditional face-to-face delivery. Students are provided with blank work sheets to solve 
problems on their own, along with a worked out solution. In addition, video problem narrations are supplied. Students are able to follow along as the instructor works through the problem.

Lectures are available for review of fundamental concepts. Lecture notes are also delivered, along with blank handouts that can be completed by the student as they listen to the narration.

\section{ENGINEERING 1030: ENGINEERING GRAPHICS AND DESIGN}

\subsection{Course Description}

Engineering 1030 provides an introduction to the fundamentals of graphic communication, including orthographic projections, three-dimensional pictorials, sectioning and dimensioning using both sketching and Computer Aided Design (CAD). The course also introduces students to standard design methodologies. Both the graphics and design competencies are reinforced through lab and project exercises.

\subsection{Online Resources}

Engineering 1030 is an on-campus course, taught mainly through a combination of face-to-face lectures and labs. The instructor, having identified a need to improve the instruction of the CAD software portion of the course. applied for, and received, an Instructional Design Grant (IDG) of $\$ 5000$

The primary objective of this project was to enhance and innovate teaching tools available to students, while improving the learning experience and advancing curriculum outcomes. Learning software in a group setting can be challenging. Student enrolment in ENGI 1030 averages approximately 350 students per year. The traditional approach sees the instructor leading a large group through complex multi-step activities, within a set time period. The challenges to the instructor and student include multiple learning styles, large class size, English as a second language, international students' learning requirements, and the limitations of the physical lab layout \& ancillary equipment. Real-time lab demonstrations offer students little opportunity to "rewind" if critical steps are missed.

While it is necessary to support student learning in a face-to-face environment, online screencasts offer a selfpaced approach and address many of the above challenges. Screencasts support student learning by clearly outlining learning objectives and are readily available, outside of the lab slot, online. They are useful when reviewing a task or preparing for tests, helpful to ESL students, and consistent in quality. As students learned online, the instructor was able to direct special attention to support learning, while it was in progress in the lab. Screencasts allowed students to independently develop their CAD skills and their ability to use engineering tools to communicate technical information, while developing life-long learning skills and becoming self-educators. This is of particular importance, as professional engineers require the ability to self-educate with respect to engineering-related software in order to remain current with industry trends and software upgrades.

An Engineering work term student, experienced with CAD, was hired to deliver a suite of screencasts. The screencasts were designed and developed by the lab instructor and the engineering work term student scripted, narrated and recorded them using Adobe Captivate 6 . Based on preliminary surveys conducted with previous ENGI 1030 students in March 2012, students were asked to topics they felt required additional support. Survey results provided initial direction on key areas for development of the screencasts.

\subsection{Survey Results}

In December 2013 an anonymous online survey was conducted to assess the impacts of the screencasts on learning. The survey had a $91 \%$ participation rate representing 175 participants of a possible 192 . 89\% of students responded positively when asked to describe how the videos helped them to teach themselves CAD. The survey also evaluated the achievement of student learning outcomes by category: 3D Modelling, Detail Drawing, Assembly, and Assembly Drawing. Within each category, at least $85 \%$ of students either agreed or strongly agreed that they achieved the learning outcomes, and that the screencasts helped them in doing so.

Two screencasts were specifically developed to highlight how CAD is used as a communication tool in hands-on workshop activities. Students were asked to rate how effective these screencasts were in helping them achieve the learning outcomes. In both cases, over $90 \%$ of students agreed that the videos helped them understand that $\mathrm{CAD}$ is an important communication tool for engineers.

Students were asked to rank the three types of teaching techniques used in the ENGI 1030 Lab: Live demonstrations, written tutorials, and screencast learning videos. $78 \%$ of students ranked the screencasts as their preferred choice of teaching technique.

Students made many positive comments about the videos in the survey such as:

\footnotetext{
"The videos were the best part of the course. You could pause if you got lost, rewind, or even skip ahead if you wanted to take something on yourself...it let you learn at your own pace, and it definitely was the most constructive for me.
} 
The videos were absolutely awesome. I especially loved when it showed more than one way to do things, this way you could explore and see what you found best, and what works best with what you are doing..."

"They let me pause and rewind so that I could follow every step at my own pace."

"For tutorials, I followed more blindly but for the videos, I felt more engaged."

\subsection{Project Outcomes}

As a result of the project and the Instruction Design Grant, 27 screencasts are now housed in a ENGI 1030 online perpetual lab. A library of all the screencasts is also available through the Cahill Engineering One Help Centre to support students of all disciplines in the engineering program. Student can access the videos at any point during their program, be it on a work term, or for their senior design project. The videos are also available for repurposing through Memorial University's STOR (learning object repository for digital learning objects).

This type of blended learning can be applied well beyond the ENGI 1030 lab environment and can be broad reaching in engineering lab learning. Screencasts can be created for a variety of lab environments offering students self paced, internet accessible, reviewable material tied to learning objectives and rubrics, D2L quizzes and self assessment tools. For example, screencasts for a multistep complex demonstration, such as the operation of machine shop equipment, can be made available prior to entering a lab. This builds confidence, clarifies learning outcomes and addresses safety concerns before the student steps into the lab environment. This is one example of the many applications that we foresee in Engineering and Applied Science labs.

\section{ENGINEERING 8151: TECHNOLOGY, SUSTAINABLE SOCIETY AND INTERNATIONAL DEVELOPMENT}

\subsection{Course Description}

This course examines multidisciplinary planning on technical international development projects through the conceptual frameworks of international development and project implementation theory. Emphasis is placed on analysis of the complex relationships between society, culture, economic, environmental and political factors, and technology to achieve sustainable international development objectives.

\subsection{Learning Outcomes}

Upon successful completion of Engineering 8151, students will be able to:

1. describe the historical experience of foreign aid, and the role of the international community in international development,

2. analyze the impact of social, cultural, political and environmental factors on international development project implementation and sustainability,

3. describe socio-cultural and environmental community-based planning methodologies,

4. discuss the importance of multi-disciplinary collaboration for design and implementation of appropriate, sustainable international development projects,

5. apply the Harvard Analytical Framework for socio-cultural and gender analysis,

6. apply professional ethics to the practice of international development.

\subsection{Online Resources}

ENGI 8151 uses online videos to introduce students to course topics and build a sense of connection with the instructor. Notes are provided as text in the online course shell, supplemented with video lectures by the instructor and Skype interviews with leading experts in international development. Short documentary videos are also included to highlight special course topics. Graphics, including interactive maps and diagrams, supplement course notes, readings and online lectures.

Discussion groups are a key element of ENGI 8151. Students are divided into groups of 4 or 5 students and they are introduced to topics in the course that are intended to encourage discussion and debate. Each group is comprised of students from a variety of engineering disciplines. The learning outcomes for this course require students to describe, discuss, analyze and apply various concepts related to technology, sustainable society and international development. Discussion groups with assigned topics are conducted each week of the course. These topics include scenarios and ethical dilemmas. Students are assessed based on their contributions the discussion, including:

1. the extent to which their contributions reflect preparedness with respect to the assigned readings,

2. contributions to the agenda of clarifications and discussion questions,

3. contributions to the social dynamic of the discussion, including listening to others and respecting their right of expression. 
As students progress through discussion topics and scenarios, they are building a sense of community within their interdisciplinary group. This group then works together to complete a group project and research paper.

\subsection{Survey Results}

An online survey is conducted at the beginning and end of each offering of ENGI 81651 to measure the interest level of students in various topics. The Winter 2013 offering saw an increase in a desire for interdisciplinary collaboration. In the baseline survey, $15 \%$ of students ranked interdisciplinary collaboration as a priority. At the end of the course, $100 \%$ of survey respondents agreed or strongly agreed that they were interested in working collaboratively with other disciplines. At the beginning of the course, $19 \%$ of students ranked Gender Issues in the Global South as an area of interest, with $0 \%$ selecting it as their top choice. At the end of the course, $77 \%$ of students ranked it as their top or second choice. Similar results applied to Environmentalism and Sustainability in the Global South. The level of interest in this topic as a first or second choice rose from $45 \%$ to $100 \%$.

\section{CONCLUSION}

Developing online or blended courses in engineering can be challenging, but the use of technology can be used to create rich and engaging environments for students. In technical courses like ENGI 1010 and ENGI 1030, online resources can be used to support on-campus learning. Students can view lectures several times to review material, watch videos to learn new skills, and rewind and repeat as necessary. Students can follow along as their instructors solve problems, and review the material again on their own. They are able to establish lifelong learning skills as they work independently.

In courses like ENGI 8151, learning communities are established online linking students around the world and across engineering disciplines to engage in active discussion and debate. As they do, they are developing graduate attributes such as lifelong learning, ethics and equity, teamwork, professionalism and sustainability.

\section{References}

[1] K. Parker, A. Lenhart and K. Moore, "The digital revolution and higher education," [Online]. Available: http://www.pewinternet.org/2011/08/28/the-digitalrevolution-and-higher-education/

[2] A. Gonzalez, M. Rodriguez, S. Olmos, M. Borham, and F. Garcia, "Experimental evaluation of the impact of b-learning methodologies on engineering students in Spain," Computers in Human Behavior, vol. 29, 370-377, 2013.

[3] A. Da Silva, N. Kuri, and A. Casale, "PBL and B-Learning for civil engineering students in a transportation course," Journal of Professional Issues in Engineering Education and Practice, vol. 138, no. 4, pp. 305-313, 2012.

[4] H. Abdalla, A. J. Martins Soares, D. Garrosini, and L. Molinaro. "Experiences of applying a blended learning approach to teaching optical communication systems." International Journal of Electrical Engineering Education, vo.l 49, no. 2, pp. 136145, 2012.

[5] D. Perez-Marin, and I. Pascual-Nieto, "A case study on the use of blended learning to encourage computer science students to study. Journal of Science Education and Technology, vol. 21, pp. 74-82, 2013.

[6] Engineers Canada. "Accreditation criteria and procedures", Ottawa, ON, 2008. 